\title{
Effect of initial notch orientation on fracture toughness in fail-safe steel
}

\author{
Tadanobu Inoue $\cdot$ Yuuji Kimura
}

Received: 13 July 2012/ Accepted: 6 September 2012/Published online: 6 October 2012

(c) The Author(s) 2012. This article is published with open access at Springerlink.com

\begin{abstract}
A 0.4C-2Si-1Cr-1Mo steel bar with an ultrafine-elongated grain (UFEG) structures was produced by multi-pass warm caliber rolling. The test sample was machined from the rolled bar with $0^{\circ}, 45^{\circ}$, and $90^{\circ}$ rotation along the rolling direction, and a static three-point bending test was conducted at ambient temperature. The toughness anisotropy on the steel with UFEG structures were studied, including the crack propagation on the basis of the microstructural features. The strength and toughness decreased with an increase in the rotation angle along the rolling direction. The toughness decreased drastically, compared to the strength. The notch orientation dependence on toughness is due to differences in the spatial distribution of weak sites such as $\{100\}$ cleavage planes and boundaries of elongated grains. For the toughness design in ultrafine-grained materials, it is essential to understand the spatial distribution of these weak sites as well as the grain size.
\end{abstract}

\section{Introduction}

Achieving strength and toughness in materials, that is, high strength in combination with resistance to fracture, is one of an eternal issue in the field of structural metallic materials. Since strengthening of materials reduces toughness [1-3], the idea for improving strength-toughness balance is always sought. It is reported that the refinement of crystal grains is an effective method for developing strength and toughness in metallic materials without the addition of

T. Inoue $(\bowtie) \cdot$ Y. Kimura

National Institute for Materials Science, 1-2-1, Sengen,

Tsukuba 305-0047, Japan

e-mail: INOUE.Tadanobu@nims.go.jp alloying elements. However, compared with microstructure evolution through severe plastic deformation (SPD) and strengthening by grain refinement, there have been few studies on their toughness. The study of toughness is far more important in the development of ultrafine-grained (UFG) materials for structural and other applications.

Although a reduction in the grain size leads to higher strength on the basis of the Hall-Petch relation, it does not always lead to the improvement of toughness. In recent grain refinement studies, Hohenwarter et al. [4] showed that the ductile-to-brittle transition temperature, DBTT, was higher for submicrocrystalline grain sizes than for microcrystalline microstructures through a compact tension test for UFG armco iron processed by high-pressure torsion (HPT) and subsequent heat treatments. Furthermore, they showed that the fracture toughness depends strongly on crack orientations machined from the HPT disk. Toker et al. [5] indicated the significant effect of anisotropy on the impact toughness of UFG niobium-zirconium alloys processed by equal-channel angular extrusion. We $[3,6,7]$ developed stronger, tougher steel, i.e., fail-safe steel, by a microstructural design based on heterogeneity that was lacking in the traditional concept. In fail-safe steel, the strengthening is attributed to ultrafine-elongated grains with nanometer-sized carbides, and the toughening is attributed to extrinsic fracture mechanisms of the crackarrester type [3, 8-10], in which the propagation of a main crack associated with the heterogeneous microstructure with a strong $\alpha$-fiber $(\mathrm{RD} \|\langle 101\rangle)$ texture is arrested. Namely, the property of toughness is sensitive to not only the size of crystal grains but also their orientation and shape because the fracture behavior is different by these microstructural parameters $[2-7,10,11]$. The fail-safe steel might also have an orientation dependence on the toughness because the microstructure consists of elongated 
grains and the spatial distribution of the $\{100\}$ plane, which is a cleavage plane in bcc iron, changes. It is of interest to systematically study the effect of crack orientations on the toughness of fail-safe steel with ultrafineelongated grain (UFEG) structures.

In the present study, a $0.4 \mathrm{C}-2 \mathrm{Si}-1 \mathrm{Cr}-1 \mathrm{Mo}$ steel bar with a UFEG structure was produced by multi-pass warm caliber rolling (WCR). The test sample was machined from the rolled bar with $0^{\circ}, 45^{\circ}$, and $90^{\circ}$ rotation along the rolling direction, and a static three-point bending test was conducted at ambient temperature. The effect of the initial notch orientation on toughness was studied, including the crack propagation on the basis of the microstructural features in the rolled bars. The anisotropic properties in the fail-safe steel were thus clarified.

\section{Experimental}

A low-alloy steel with a chemical composition of $0.39 \mathrm{C}$, $2.01 \mathrm{Si}, 1.02 \mathrm{Cr}, 1.0 \mathrm{Mo}, 0.21 \mathrm{Mn},<0.001 \mathrm{P},<0.001 \mathrm{~S}$, $0.004 \mathrm{Al}, 0.0022 \mathrm{~N}, 0.001 \mathrm{O}$, and the balance $\mathrm{Fe}$ (all in mass\%) was used in this study. A $100 \mathrm{~kg}$ ingot was prepared by vacuum induction melting and casting, homogenized at $1473 \mathrm{~K}$, and then hot rolled to a 40-mm thickness plate. A block, $40-\mathrm{mm}^{2}$ and $120-\mathrm{mm}$ long, was cut out of the plate, solution treated at $1473 \mathrm{~K}$ for $3600 \mathrm{~s}$ to reduce undissolved carbide particles and then hot rolled into a bar of about 31-mm square, followed by water quenching to obtain the martensitic structure. The quenched bar was soaked at $773 \mathrm{~K}$ for $1 \mathrm{~h}$, immediately subjected to a caliber rolling simulator [12] of the square/square type without any lubricant, and then air-cooled. Note that the sample was held for $0.3 \mathrm{ks}$ in a furnace after three passes during the rolling and passed through twice for the final groove to control the cross-sectional shape of the bar. Eventually, a $14.3 \times 14.3 \times 930 \mathrm{~mm}^{3}$ rolled bar was produced. Hereafter, this sample is designated as the TF sample. To obtain quenched and tempered samples with the same tensile strength for comparison, a normalized bar was solution treated at $1223 \mathrm{~K}$ for $0.5 \mathrm{~h}$, followed by oil quenching. Next, the bar was tempered at $773 \mathrm{~K}$ for $1 \mathrm{~h}$ and then water cooled. Hereafter, this sample is designated as the QT sample. The principal axes of the rolled bar in this study are defined as shown in Fig. 1a. The axis corresponding to the rolling direction is defined as the $\mathrm{RD}$; that corresponding to the direction of the main working force at the final pass is ND; and that which is normal to the RD is defined as TD1 and TD2.

The appearance of specimens after the three-point bending test was observed through a digital camera, and fracture surfaces on the specimens were observed through a scanning electron microscope (SEM) operated at $15 \mathrm{kV}$. (a)
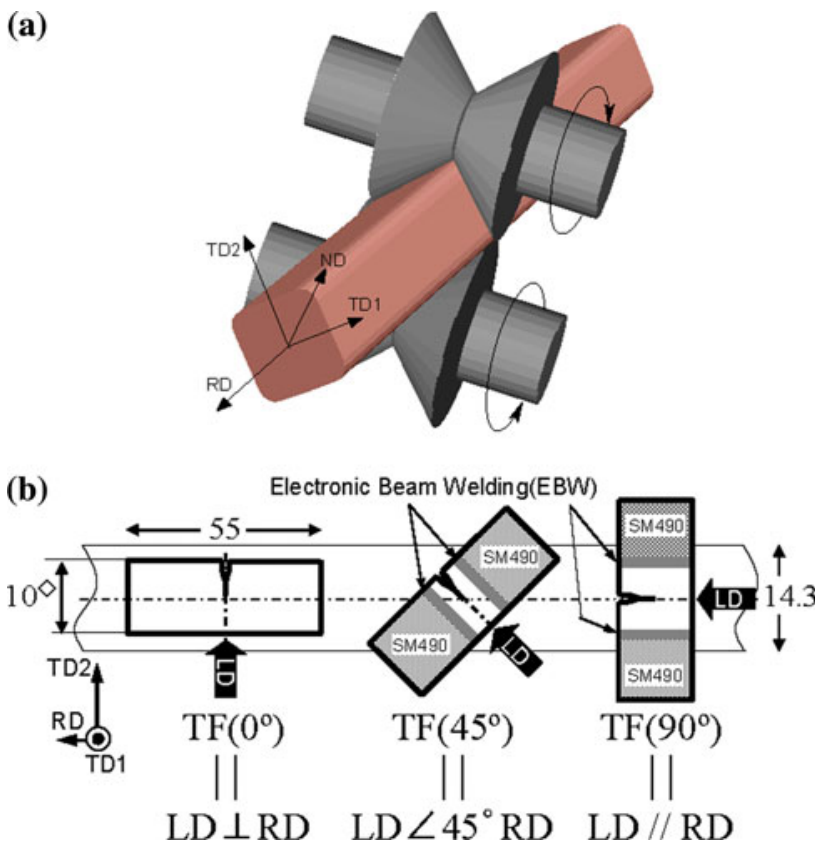

Fig. 1 a Schematic drawing of the caliber rolling used in the present study and $\mathbf{b}$ crack plane orientation code taken from the rolled bar

The microstructures in the central parts of the cross sections in the rolled bars were observed by the electron backscattered diffraction (EBSD) method in an SEM equipped with a field emission gun.

To clarify the notch orientation effect on the toughness, specimens used in a three-point bending test were taken from the rolled bar with $0^{\circ}, 45^{\circ}$, and $90^{\circ}$ rotation along the $\mathrm{RD}$, and then both ends of the samples were bonded to a low-carbon steel, SM490, through electronic beam welding (EBW). Rectangular bars of $10 \times 10 \times 55 \mathrm{~mm}^{3}$ were machined for all specimens, and then a notch with a depth of $a_{0}=5 \mathrm{~mm}$ and a root radius of $\rho=0.13 \mathrm{~mm}$ was introduced by electro-discharge machining with fine wire $0.1 \mathrm{~mm}$ in diameter. A notch tip in all test specimens was positioned at the center of the RD plane. The relation between the RD and the loading direction (LD) in each test sample is illustrated in Fig. 1b. The crack orientation in the $\mathrm{TF}\left(0^{\circ}\right)$ sample is normal to the $\mathrm{RD}$ that in the $\mathrm{TF}\left(45^{\circ}\right)$ sample has an angle of $\sim 45^{\circ}$ to the RD, and that in the $\mathrm{TF}\left(90^{\circ}\right)$ sample is parallel to the RD. The shape and dimensions of three-point bending test and OM image near the notch root of the test specimen are illustrated in Fig. 2. The three-point bending test with a support distance of $40 \mathrm{~mm}$ at a cross-head speed of $0.05 \mathrm{~mm} \mathrm{~min}^{-1}$ was conducted at ambient temperature. The load-displacement response was recorded at a time step of $0.05 \mathrm{~s}$. Nonlinear fracture mechanics methods based on ASTM Standard E1820-01 [13] were used to evaluate the fracture toughness. The apparent fracture energy, $J$, was calculated by the following formula: 
Fig. 2 Shape and dimensions of three-point bending test and OM image near the notch root of the test specimen

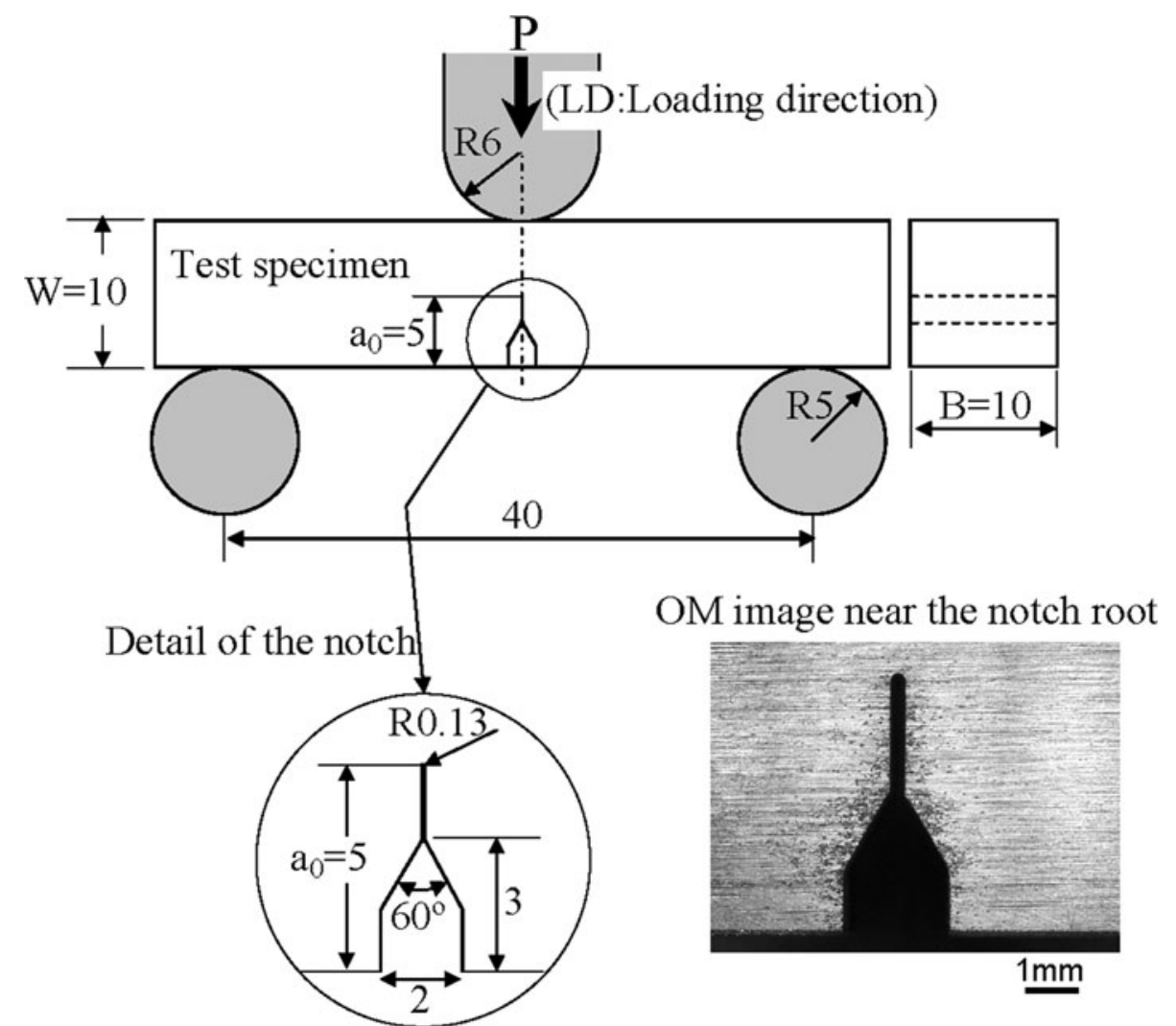

$J=\frac{2 A_{\mathrm{pl}}}{B b}=\frac{2}{B b} \int_{0}^{u_{\mathrm{F}}} P \mathrm{~d} u$,

where $A_{\mathrm{pl}}$ is the area under the load $P$-displacement $u$ curve, $B$ is the specimen thickness, $b$ is the ligament length $\left(W-a_{0}\right)$, and $u_{\mathrm{F}}$ denotes the displacement at which the test was terminated. All the values presented represent an average of two or three measurements.

Small plate samples with parallel length of $4 \mathrm{~mm}$, a width of $3 \mathrm{~mm}$, and a thickness of $1 \mathrm{~mm}$ were also machined from the bars with $0^{\circ}, 45^{\circ}$, and $90^{\circ}$ rotation along the RD and used for tensile testing at ambient temperature at a cross-head speed of $0.11 \mathrm{~mm} / \mathrm{min}$ to investigate the strength anisotropy of the TF sample. Details of the configuration of small samples were given earlier [14].

\section{Results and discussion}

The static mechanical properties, including fracture toughness, $J$, are summarized in Table 1 . In the $\operatorname{TF}\left(0^{\circ}\right)$ sample, the tensile properties of the small plate specimens were similar to the results [3] of the JIS 14A specimens with a round cross section of $6 \mathrm{~mm}$ and a gage length of $30 \mathrm{~mm}$. As expected, the TF samples exhibited an anisotropic tensile behavior due to the unique hierarchical anisotropic nanostructures, in contrast to the QT sample with an isotropic microstructure [14]. The yield strength, $\sigma_{\mathrm{ys}}$, decreased with an increase in the rotation angle along the RD. The $\sigma_{\text {ys }}$ of the $\operatorname{TF}\left(90^{\circ}\right)$ sample was about $16 \%$ lower than that of the $\operatorname{TF}\left(0^{\circ}\right)$ sample. Similarly, the $J$ also decreased with the rotation angle along the RD, but these $J$ decreased drastically, compared to the strength. Although the $J$ of the $\mathrm{TF}\left(45^{\circ}\right)$ sample was somewhat higher than that of the QT sample, the $\mathrm{TF}\left(90^{\circ}\right)$ sample exhibited the lowest toughness of $44 \mathrm{~kJ} / \mathrm{m}^{2}$ among the present four samples despite the lowest tensile strength of $1.67 \mathrm{GPa}$, and the toughness was about $99 \%$ lower than that of the $\operatorname{TF}\left(0^{\circ}\right)$ sample which caused delamination by crack branching.

Figure $3 \mathrm{a}$ presents the bending load $P$-displacement $u$ curves for the $\operatorname{TF}\left(45^{\circ}\right)$ and $\operatorname{TF}\left(90^{\circ}\right)$ samples and, for comparison, the curves [3] for the $\operatorname{TF}\left(0^{\circ}\right)$ and the QT samples. Figure 3b-d show the appearances of the TF samples after the test, and Fig. 3e the SEM micrograph of fracture surface in the $\mathrm{TF}\left(90^{\circ}\right)$ sample. $\mathrm{The} \operatorname{TF}\left(90^{\circ}\right)$ sample catastrophically fractured with a peak loading, $P_{\max }$, of $6.9 \mathrm{kN}$, such as the QT sample with $P_{\max }=12.3 \mathrm{kN}$. It 
Table 1 Static mechanical properties at ambient temperature for $\operatorname{TF}\left(0^{\circ}\right), \operatorname{TF}\left(45^{\circ}\right)$, and $\operatorname{TF}\left(90^{\circ}\right)$ samples illustrated in Fig. $1 \mathrm{~b}$ and $\mathrm{QT}$ sample

\begin{tabular}{llllrl}
\hline & $\begin{array}{l}\text { Notch } \\
\text { orientation }\end{array}$ & $\begin{array}{l}0.2 \% \text { yield strength, } \\
\sigma_{\mathrm{ys}}(\mathrm{GPa})\end{array}$ & $\begin{array}{l}\text { Tensile strength, } \\
\sigma_{\mathrm{B}}(\mathrm{GPa})\end{array}$ & $\begin{array}{l}\text { Fracture energy, } \\
\mathrm{J}\left(\mathrm{kJ} / \mathrm{m}^{2}\right)\end{array}$ & $\begin{array}{l}\text { Strength-toughness balance } \\
\sigma_{\mathrm{ys}} \times \mathrm{J}\left(\mathrm{GPa} \times \mathrm{kJ} / \mathrm{m}^{2}\right)\end{array}$ \\
\hline TF sample & $0^{\circ}$ (Ref. [3]) & 1.86 & 1.86 & 5184 & 9642 \\
& $0^{\circ}$ & $1.86^{\mathrm{a}}$ & $1.87^{\mathrm{a}}$ & 5184 & 9642 \\
& $45^{\circ}$ & $1.71^{\mathrm{a}}$ & $1.75^{\mathrm{a}}$ & 142 & 243 \\
& $90^{\circ}$ & $1.56^{\mathrm{a}}$ & $1.67^{\mathrm{a}}$ & 44 & 69 \\
QT sample & $0^{\circ}$ (Ref. [3]) & 1.51 & 1.82 & 129 & 195 \\
\hline
\end{tabular}

${ }^{a}$ Tensile test at small plate specimen

Fig. 3 a Bending load $P$-displacement $u$ curves at ambient temperature. b-d Appearance of sample after the bending test. Here, all pictures are close-ups to illustrate the feature near the notch. e SEM micrograph of the fracture surface of $(\mathbf{d})$

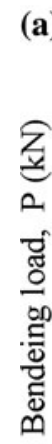

(a)

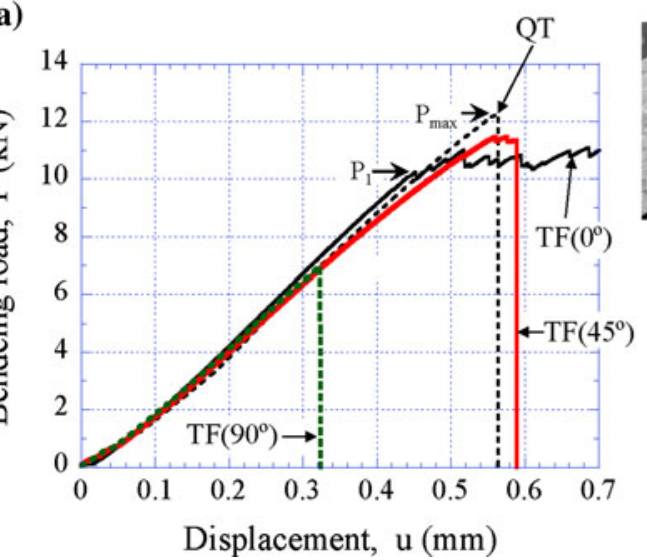

(b) $\operatorname{TF}\left(0^{\circ}\right)$ Crack branching (c) $\operatorname{TF}\left(45^{\circ}\right)$

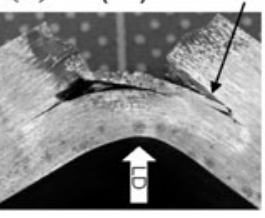

(d) $\operatorname{TF}\left(90^{\circ}\right)$

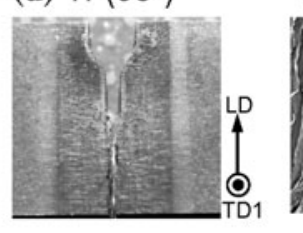

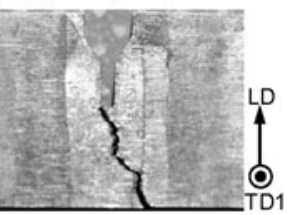

(e)

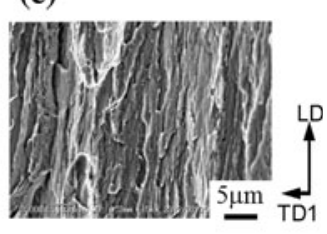

thus showed typical brittle fracture behavior, and the cracks propagated directly across the center part of the test bar (Fig. 3d). On the other hand, in the $\operatorname{TF}\left(45^{\circ}\right)$ sample, the first load drop occurred at loading, which was smaller than the $P_{\max }$ of the QT sample and larger than the $P_{\max }$ of the $\mathrm{TF}\left(90^{\circ}\right)$ sample, and then a couple of load drops appeared. Eventually, the sample fractured into two pieces. The fracture path that was composed of cracks with an angle of $\sim 45^{\circ}$ to the $\mathrm{LD}\left(\mathrm{crack} \angle 45^{\circ} \mathrm{LD}\right)$ and parallel to the $\mathrm{LD}$ (crack $\|$ LD) was observable, as shown in Fig. 3c. Namely, the $\mathrm{TF}\left(45^{\circ}\right)$ sample did not show a typical catastrophic fracture as the $\operatorname{TF}\left(90^{\circ}\right)$ and QT samples did.

Figure 4 shows the image-quality map obtained by the EBSD analysis on the cross section of the plane along the RD for the TF sample and the inverse pole figures for the RD and TD2. Here, the $\{100\}\langle 110\rangle$ texture and $\{110\}\langle 110\rangle$ texture that cause delamination by crack branching in the $\operatorname{TF}\left(0^{\circ}\right)$ sample [6, 10, 15] are highlighted in EBSD map, and the LD for each sample is illustrated. The insets in Fig. 4 show that the $\{100\}\langle 110\rangle$ texture has a cleavage plane parallel to the RD and the $\{110\}\langle 110\rangle$ texture has a cleavage plane with an angle of $\pm 45^{\circ}$ to the RD. The fraction of $\{100\}\langle 110\rangle$ texture and $\{110\}\langle 110\rangle$ texture was 20 and $34 \%$, respectively, under a tolerance angle of $15^{\circ}$. Although the fraction of the $\{100\}\langle 110\rangle$ texture is smaller than that of the $\{110\}\langle 110\rangle$ texture, grain boundaries parallel to a cleavage plane of the elongated $\{100\}\langle 110\rangle$ grains are existent. A smaller grain microstructure provides a higher density of grain boundaries. In the TF sample, the transverse size of the elongated ferrite grains was $310 \mathrm{~nm}$ [3]. Hence, a crack related to a brittle fracture may preferentially propagate at these weak sites that are aligned in the RD.

The coherence length on the $\{100\}$ cleavage plane parallel to the RD in the $\{100\}\langle 110\rangle$ grains is longer than that in the $\{110\}\langle 110\rangle$ grains because of the elongated grains. A brittle fracture occurs when the effective yield stress in the process zone at the notch tip exceeds the cleavage fracture stress (transgranular brittle fracture stress) or the grainboundary fracture stress (intergranular brittle fracture stress). These fracture stresses increase with a reduction in the average grain size, and this grain-size dependence is higher than the grain-size dependence of a yield stress [16]. According to the Griffith equation, the brittle fracture stress, $\sigma_{\mathrm{F}}$, related to these weak sites is a function of the cohesive energy of fracture, $\gamma$ (in this case, the cohesive energy along the cleavage plane and the grain-boundary cohesive 
Fig. 4 Image-quality map on the cross-sectional plane parallel to the RD for the TF sample and inverse pole figures for the RD and TD2

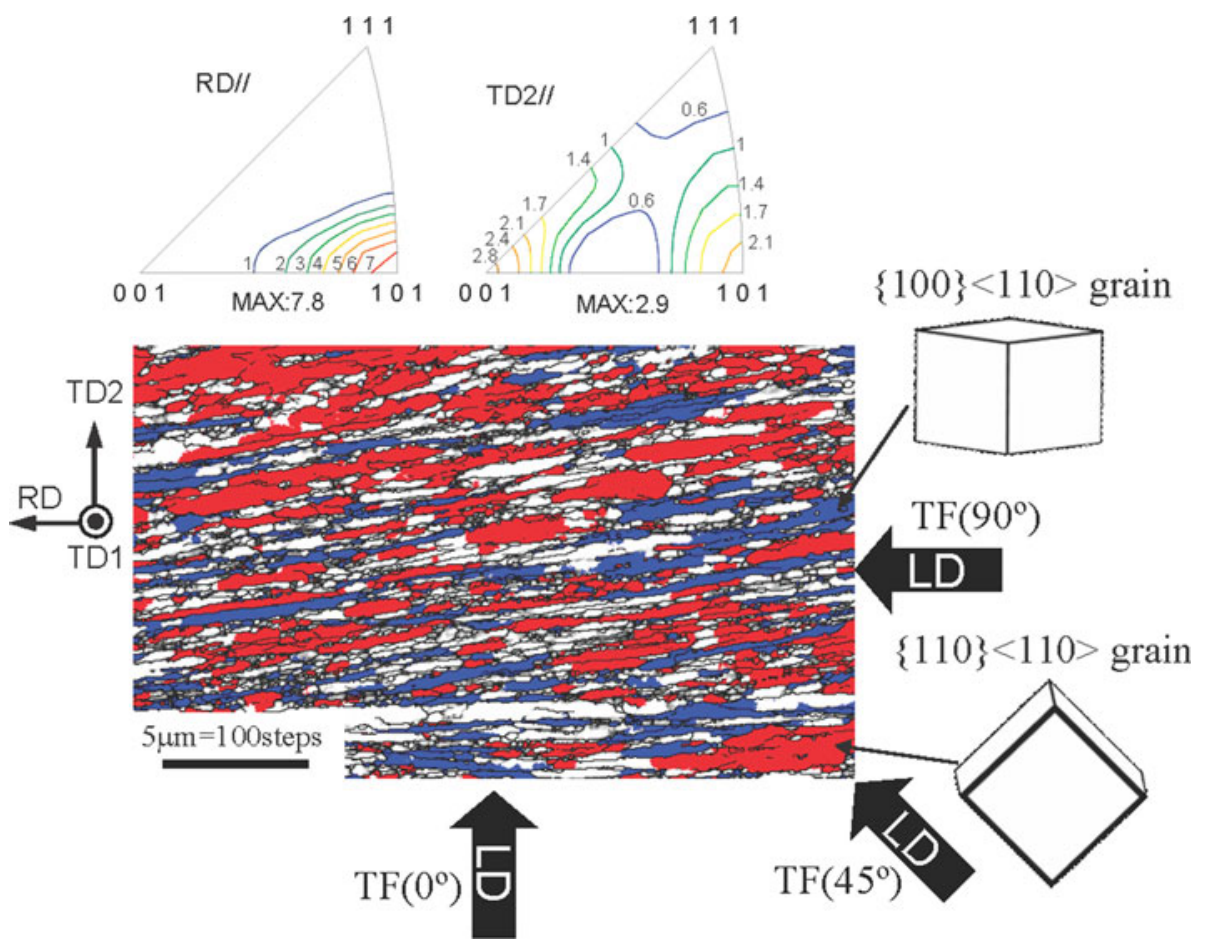

Fig. 5 Schematic illustrations of a tensile stress triaxiality near the notch under the plane strain condition and $\mathbf{b}-\mathbf{d}$ of fracture stress in notch direction for the elongated grains with a strong $\mathrm{RD} \|\langle 101\rangle$

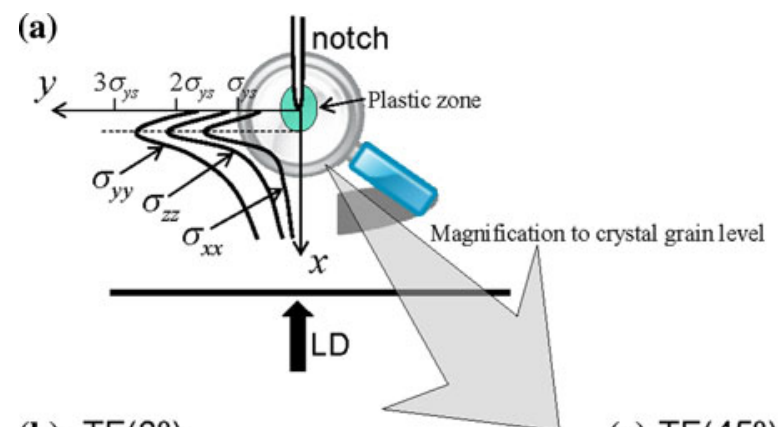

(b) $\operatorname{TF}\left(0^{\circ}\right)$

(c) $\operatorname{TF}\left(45^{\circ}\right)$

(d) $\operatorname{TF}\left(90^{\circ}\right)$

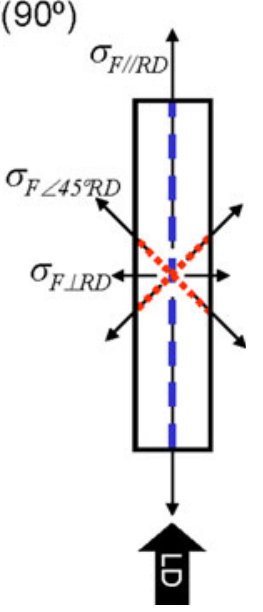

energy), and the crack size (in this case, it is replaced by the effective grain size, $d_{\mathrm{eff}}$ ) [16-18]. These have a relation of $\sigma_{\mathrm{F}} \propto \gamma^{(1 / 2)} \times d_{\mathrm{eff}}^{(-1 / 2)}$; i.e., $\sigma_{\mathrm{F}}$ becomes larger with decreasing $d_{\text {eff. }}$ For the TF sample with the UFEG structure, the brittle fracture stresses in each direction illustrated in Fig. $5 \mathrm{~b}-\mathrm{d}$ are expressed by a relation of $\sigma_{\mathrm{F} \perp \mathrm{RD}} \ll \sigma_{\mathrm{F} \angle 45^{\circ} \text { - }}$ $\mathrm{RD}<\sigma_{\mathrm{F} \| \mathrm{RD}}$. If the Tresca yield criterion is assumed in the process zone within the plastically yielding region of the 
notch tip, the triaxial tension stress in the plane strain condition is represented by the following:

$\left\{\begin{array}{l}\sigma_{z z}=0.5\left(\sigma_{x x}+\sigma_{y y}\right) \\ \sigma_{y y}=\sigma_{y s}+\sigma_{x x}\end{array}\right.$

As a result, the yield stress of the notched specimen is greater than the uniaxial yield stress, $\sigma_{\mathrm{ys}}$, shown in Table 1. The maximum value of each stress component found at the elastic-plastic interface in the process zone is expressed by $\sigma_{x x(\max )} \approx 1.6 \sigma_{\mathrm{ys}}, \sigma_{y y(\max )} \approx 2.6 \sigma_{\mathrm{ys}}$, and $\sigma_{z z(\max )} \approx 2.1 \sigma_{\mathrm{ys}}$ $[17,19]$ although these exact values have to be calculated through numerical simulations because the stresses depend on the geometry of the notch tip, ligament length, specimen thickness, and anisotropic properties. In addition, the stresses in the process zone have the distribution shown in Fig. 5a [20]. Here, the axis parallel to the LD is defined as $x$ and the one normal to the LD is $y$. In general, a crack propagates parallel to the LD because the tensile stress, $\sigma_{y y}$, vertical to the $\mathrm{LD}$ occurs by a bending load. In the $\operatorname{TF}\left(0^{\circ}\right)$ sample shown in Fig. 3b, the crack did not propagate parallel to the LD because a cleavage plane was almost nonexistent along the LD under the structures with $\alpha$-fiber texture. A delaminating crack related to a brittle fracture induced by $\sigma_{x x}>\sigma_{\mathrm{F} \perp \mathrm{RD}}$ occurred before a ductile fracture (Fig. $5 \mathrm{~b}$ ). This phenomenon appeared as the first drop $P_{1}$ and a subsequent load increase (Fig. 3a). Namely, the boundaries of elongated grains lying normal to the initial crack orientation and the $\{100\}$ cleavage planes constituted a barrier against crack propagation along the LD. Eventually, its $J$ increased remarkably due to this crack branching. In contrast, in the $\mathrm{TF}\left(90^{\circ}\right)$ sample, the tensile direction of the stress, $\sigma_{y y}$, induced by a bending load corresponds to the direction of the lowest brittle fracture stress, $\sigma_{\mathrm{F} \perp \mathrm{RD}}$ (Fig. 5d); therefore, the fracture was dominated by crack path parallel to the LD, as shown in Fig. 3d. At this time, in the fracture surface, microscopically, not only a cleavage plane related to $\{110\}\langle 110\rangle$ grains but also a fracture plane (fine dimple) associated with a plastic deformation was observable, together with crack $\|$ LD. This fracture surface characterized by a quasi-cleavage shown in Fig. 3e was very similar to the delaminating structure observed in the $\mathrm{TF}\left(0^{\circ}\right)$ sample [3, 14, 15]. Eventually, the peak-bending load exhibited the lowest value and the $J$ decreased remarkably because a barrier lying normal to crack propagation is nonexistent. In the $\mathrm{TF}\left(45^{\circ}\right)$ sample, the cleavage plane of the $\{110\}\langle 110\rangle$ grains is existent along the LD, as shown in Fig. 5c. However, the crack first propagated along an angle of $\pm 45^{\circ}$ to the $\mathrm{LD}$ due to $\sigma_{\mathrm{F} \perp \mathrm{RD}} \ll \sigma_{\mathrm{F} \angle 45^{\circ} \mathrm{RD}}$ and $\sqrt{\sigma_{x x}^{2}+\sigma_{y y}^{2}}>\sigma_{y y}>\sigma_{x x}$. Subsequently, a zigzag fracture path composed of crack $\| \mathrm{LD}$ and crack $\angle 45^{\circ} \mathrm{LD}$, macroscopically, appeared, as shown in Fig. 3c. That is, weak planes related to $\{100\}\langle 110\rangle$ grains and the boundaries of elongated grains as well as a cleavage plane parallel to LD related to $\{110\}\langle 110\rangle$ grains were induced during the bending test. Hence, the $P-u$ curves did not show typical brittle fracture behavior, and the $J$ was larger than that of the $\mathrm{TF}\left(90^{\circ}\right)$ sample due to the deflection of the crack path.

\section{Conclusions}

In conclusion, the present results demonstrated anisotropic properties in a $0.4 \mathrm{C}-2 \mathrm{Si}-1 \mathrm{Cr}-1 \mathrm{Mo}$ steel with ultrafineelongated grain structure. The strength and the toughness decreased with an increase in rotation angle along the rolling direction, especially, the toughness decreased remarkably compared to the strength. The notch orientation dependence on toughness is due to differences in the spatial distribution of weak sites, such as $\{100\}$ cleavage planes and boundaries of elongated grains. For the toughness design of fail-safe steel, it is essential to understand the spatial distribution of these weak sites as well as the grain size.

Acknowledgement We thank S. Kuroda, Y. Taniuchi, and K. Nakazato for materials processing, T. Kanno and G. Aragane for sample preparation of three-point bending test including welding, Ms. E. Motoki for her experimental assistance in the microstructural observations, and Ms. Y. Yano for her illustration used in this paper. This study was partly supported by the grants from the JFE 21st Century Foundation, and KAKENHI B (No. 23360312). These grants are gratefully appreciated.

Open Access This article is distributed under the terms of the Creative Commons Attribution License which permits any use, distribution, and reproduction in any medium, provided the original author(s) and the source are credited.

\section{References}

1. Lu K (2010) Science 328:319

2. Launey ME, Ritchie RO (2009) Adv Mater 21:2103

3. Inoue T, Kimura Y, Ochiai S (2012) Sci Technol Adv Mater 13:035005

4. Hohenwarter A, Kammerhofer C, Pippan R (2010) J Mater Sci 45(17):4805. doi:10.1007/s10853-010-4635-9

5. Toker SM, Rubitschek F, Niendorf T, Canadinc C, Maier HJ (2012) Scripta Mater 66:435

6. Kimura Y, Inoue T, Yin F, Tsuzaki K (2008) Science 320(5879): 1057

7. Nie Y, Kimura Y, Inoue T, Yin F, Akiyama E, Tsuzaki K (2012) Metall Mater Trans 43A:1670

8. Embury JD, Petch NJ, Wraith AE, Wright ES (1967) Trans Metall Soc AIME 239:114

9. She J, Inoue K, Ueno K (2000) J. Mater Sci Lett 19:45

10. Bourell DL (1983) Metall Trans A 14:2487

11. Rao KTV, Ritchie RO (1989) Mater Sci Technol 5:882

12. Inoue T, Yin F, Kimura Y (2007) Mater Sci Eng 66A:114

13. ASTM E1820-01 (2005) Standard test method for measurement of fracture toughness. ASTM International, West Conshohocken, pp 1036-1081 
14. Kimura Y, Inoue T, Yin F, Tsuzaki K (2010) ISIJ Int 50:152

15. Inoue T, Yin F, Kimura Y, Tsuzaki K, Ochiai S (2010) Metall Mater Trans 40A:341

16. Gilbert A, Hahn GT, Reid CN, Wilcox BA (1964) Acta Mater 12:754

17. Ma H (1998) Int J Fract 89:143
18. Kameda J, Nishiyama Y (2011) Mater Sci Eng 528A:3705

19. Matsuda S, Kawashima Y, Sekiguchi S, Okamoto M (1982) Tetsu-to-Hagane 68:435 (in Japanese)

20. Dieter GE (1988) Mechanical metallurgy SI metric edition. McGraw-Hill Book Co, Singapore, pp 265-268 